\title{
¿Debería un niño tener más de una madre? La noción de un psicólogo sobre una mejor manera de crecer
}

\section{Should a Child Have More than One Mother?}

John B. Watson

Traducción: Carlos Silva

(Publicación original: Watson, John. B. (1936). Should a Child Have More than One Mother? Liberty Magazine, june, 31-35).

[Fundador de la escuela de psicología conocida como conductismo extremo, la cual niega que el hombre tenga alma y sostiene que su personalidad, carácter y comportamiento están hechos por completo de respuestas a estímulos. Los conductistas descartan la herencia y todo lo atribuyen al ambiente, y el Profesor Watson ha declarado que si usted le da cualquier niño recién nacido sano, lo convertirá en un futuro líder en cualquier ocupación. Su nueva filosofía radical ha provocado mucha controversia. Aquí está su punto de vista sobre la crianza de los niños.]

Si usted pudiera hacer el mundo de nuevo, ¿qué cambiaría? ¿Tendría iglesias y clérigos, leyes y castigos? ¿Tendría escuelas y universidades? ¿Mantendría la institución del matrimonio —una esposa para un esposo, cada uno fiel al otro? ¿Mantendría los hogares tal como son ahora - permitiendo a los padres tener y poseer a sus propios niños y ser responsables de su crianza?

Supongo que el 99 por ciento de nosotros nunca ha cuestionado seriamente estas instituciones. Están en el corazón mismo de la civilización actual. Tan ufanos nos sentimos por ellas que cualquier invitación a siquiera pensar en su valor en el presente, genera el grito: “iMaten al lunático!" Un profesor universitario, incluso en nuestro Norte ilustrado, que se atreva a cuestionarlas pierde su trabajo tan rápidamente como lo pierde el profesor del Sur que intenta explicar la evolución. ¿Y todas estas instituciones no han fracasado completa y miserablemente desde que dejamos de ser un pueblo primitivo? ¿No seguimos cargando con ellas por inercia e ignorancia de cosas mejores que pudieran ocupar sus lugares? 
Tales pensamientos llevan al conductista a soñar con una Utopía donde los niños puedan crecer con reacciones ajustadas al presente y no a la era victoriana.

El hogar, tal como lo tenemos hoy, pienso que no se adapta al servicio del siglo veinte. Principalmente, ha fracaso porque prolonga el período de la infancia. Ninguna otra familia biológica lo prolonga así. Los cuervos viven tanto como nosotros, sin embargo sus jóvenes se independizan de los padres al cabo de pocos meses. Las cobayas jóvenes son expulsadas de sus hogares luego de pocas semanas. Los conejillos y las crías de ratas, que nacen tan indefensos como nuestros niños, van por su cuenta al final de cuatro semanas. Los monos jóvenes, nuestros familiares más cercanos en el campo animal, robarán la comida de sus madres al cabo de un año, y si ella intenta administrar un castigo debe ser realmente ágil para infligirlo.

En las fronteras y en las granjas, el joven a una edad muy temprana se convierte en un factor de producción. No es inusual, en modo alguno, ver niños en el Sur, de ocho y nueve años de edad, trabajando en los campos de algodón, y ver chicos de diez y de doce años de edad realizando tareas como pescar, cazar y tender trampas para suministrar a la familia carne fresca. Hoy, en las ciudades, a los niños ni siquiera se les enseña que existe algo como luchar por la comida. Crecen en la escuela, el liceo, la universidad sin convertirse en factores de producción necesarios para sostener un hogar.

Las mujeres (las esposas), hoy día, no tienen mucho qué hacer. La producción científica en masa ha hecho sus tareas tan fáciles que tienen demasiado tiempo de sobra. Utilizan ese tiempo para destruir la felicidad de sus hijos.

La madre comienza a destruir al niño desde el momento del nacimiento. Lo recibe como un pequeño fragmento de protoplasma. Durante los primeros años (desde el nacimiento hasta los tres), ella es la única que tiene acceso al niño. La manipulación de los padres es la única formación que recibe. Tienen que construirlo como ellos mismos — pues no conocen otra manera de construirlo. Así, cada adulto es la resultante de la influencia formativa del padre y la madre —más, por supuesto, algunos abuelos, tíos y tías.

Por lo tanto, todas las debilidades, reservas, temores, precauciones y sentimientos de inferioridad de nuestros padres se graban en nosotros con golpes de mazo. No heredamos nuestro carácter, temperamento y habilidades especiales. Son forzadas en nosotros a través de nuestros padres.

Observe el próximo niño de tres años que vea —escoja uno al azar. He aquí un caso. Es tímida; llora cuando la madre abandona la habitación; no juega con otros niños; se entretiene sólo un momento con los juguetes, luego corre hacia la madre para que la cargue, la abrace y la bese; no come sola, cada bocado requiere de un esfuerzo distinto por parte de su madre; no come los alimentos que le ponen en frente; lloriquea continuamente; no duerme sola, sino que debe tener presentes tanto a la madre como la luz hasta quedarse dormida. Esta niña no tiene ni un solo momento feliz al día. ¿Nació así? No. La madre y el padre crearon a esta niña. ¿Tiene alguna oportunidad? No la tiene en ese mismo hogar. La única esperanza para esa niña es sacarla de su hogar y colocarla en un lugar donde haya gente que tenga el sentido suficiente para tratarla como un ser humano. Tenemos evidencias experimentales buenas para demostrar que en pocos meses, por medio de una manipulación cuidadosa, esta niña podría ser completamente re-condicionada. Hay evidencia en cada clínica psiquiátrica que muestra que si no se encargan de ella (como no se encargan de la mayoría) se convertirá en un ser humano inferior, mostrando todos los rasgos de su entrenamiento infantil. 
He aquí otro niño de cuatro años temeroso hasta de su sombra. Si un perro se acerca, llora y corre hacia su niñera o hacia su madre. Cuando un extraño viene a casa, se esconde detrás de cualquier objeto; un juguete eléctrico lo aterroriza; una mariposa o un juguete mecánico hace que corra hacia los brazos de su madre o que se esconda detrás de sus faldas.

He aquí otra más; una niña de tres años de edad. Patalea y grita cuando la visten; cuando se la sujeta para que no corra por la calle o cuando intenta jugar con algo que pueda herirla. Lucha contra los sirvientes. Ninguna niñera quiere quedarse a su lado. Todo el día escuchamos a su madre decir "Niña mala —mamá tendrá que castigarte nuevamente."

¿Niños felices? ¿Felices por el tierno amor de la madre? Como Diógenes, he buscado con mi linterna niños felices. Casi diría que los he hallado felices mientras estaban durmiendo, pero incluso así no son felices. Están inquietos. Los adultos deben caminar de puntillas por la casa por temor a despertarlos. Así de ligero es su sueño.

¿Son exageraciones? Espero que sí. Tal vez mis observaciones han sido limitadas y prejuiciadas, pero mi búsqueda de un niño feliz ha sido amplia. Pocos padres de hoy saben cómo criar a sus hijos y resienten amargamente que se les diga cómo. Los crían como los criaron a ellos. Tal como ocurre con el entrenamiento temprano, los años que restan hasta la adolescencia deben pasarlo en compañía de sus padres. Los padres aún deben permanecer como los patrones primarios de formación de sus vidas.

¿Y qué con las padres? ¿Qué pasa con la relación esposo-esposa? ¿Cuántas esposas, hoy, son felices? ¿Cuántos esposos son más felices? ¿Cuántos hombres y mujeres se libran del sexo inquieto que disturba tantos hogares? Se estima que sólo el 20 por ciento de las mujeres casadas han aprendido a tener una relación sexual exitosa con sus esposos. Esto significa que hoy día en el 80 por ciento de los hogares hay inquietud e infelicidad. Los hombres saben poco o nada sobre el entrenamiento de sus esposas. La mayoría de los esposos y esposas ni siquiera son lo suficientemente francos para hablar de sus problemas e intentar un ajuste. La amargura crece. Las esposas solían sonreír y soportar la situación, pero ahora el aumento de los divorcios ha venido a resolver este problema. Pero las mujeres han sido tan pésimamente entrenadas por sus madres y los hombres por sus padres, que un nuevo matrimonio muy a menudo sólo significa un periodo de luna de miel y otro de inquietud. Por supuesto, hay otros factores además del sexo, tal como hay otros factores además del hambre. Pero el problema del pan y la carne deben resolverse antes de que el individuo se meta en otros asuntos. El problema del sexo también debe resolverse antes de que el individuo ejerza sus otras vocaciones.

Frecuentemente, sobre la base de factores económicos, la mujer no se divorcia sino que contemporiza. Celosamente vigila cada acción de su esposo. Estos hogares —el 80 por ciento, y creo que más - son lugares poco sólidos para criar a un niño. En tales hogares el esposo y la esposa recurren a la invalidez para evitar las relaciones maritales. Son hogares de quejas y llantos.

El hogar de hoy es tan destructivo, tan devastador es el amor de la madre, que algunos de nosotros creemos que debemos intentar una nueva forma de criar a nuestros jóvenes. ¿No podemos, sólo como una especulación, considerar que la identidad padres-hijo se vaya por la borda? ¿Podemos abandonar nuestra testaruda idea de poseer nuestros propios hijos, debido a que no es humanamente posible criarlos para que casen en la actual civilización si los criamos como posesiones? 
Nuestro egoísmo, lo sé, está arraigado profundamente. Queremos a nuestros hijos como queremos a nuestras casas, automóviles, caballos y perros — sea o no bueno para los niños. Hay todavía una razón arraigada con mayor profundidad por la que alegamos que los niños son sangre de nuestra sangre. Se cree que llevan consigo nuestra propia identidad a través de los tiempos, continúan nuestra propia grandeza, ayudan a engrandecernos. Esta visión se basa en la idea errónea de que nuestro comportamiento se hereda. No podemos sino pensar que nuestros hijos heredan nuestras virtudes, habilidades especiales, temperamento y talento. Nos ayudan a continuar viviendo para siempre. Es difícil alejarse de este punto de vista medieval.

Construyamos una Utopía donde podamos soñar un tipo diferente de vida familiar. ¿Puedo decir, antes de que entremos por la puerta de esta Utopía, que soy lo suficientemente chapado a la antigua para creer que la monogamia es posible (puede que no sea deseable afirmar esto en este momento) si preparamos a los chicos y chicas durante los primeros años de su vida? De cualquier modo, quiero ver que la monogamia se intente. Nunca ha sido completamente de otra manera. También soy lo suficientemente chapado a la antigua para querer salvar al menos un remanente de esa cosa que ahora llamamos "hogar". Esta Utopía no es una propaganda de ninguna causa "conocida". Los utopistas son demasiado ignorantes de "grandes causas" y de todos los asuntos políticos y económicos para saber de qué se tratan esas cosas.

La industria en nuestra Utopía va como va aquí. Hay agricultura, minería, manufactura, astilleros, etc. Las fábricas zumban tanto allí como aquí, y los hombres trabajan duro como ninguno porque están entrenados para estar absortamente activos durante las horas de vigilia. Tienen el mismo incentivo que aquí por hacer trabajo especializado: sueldos altos, son muy bien vistos por la comunidad por su buen trabajo, etc. Sin embargo, hay más tiempo para juegos y ejercicios que en el caso de otras naciones. La riqueza se acumula tanto allá como aquí. La diferencia extraordinaria es que la riqueza heredada no está permitida, debido a sus efectos devastadores en la generación subsiguiente.

Los utopistas no son comunistas ni capitalistas, ni laboristas, ni marxistas, ni cristianos, ni católicos, ni judíos, ni mahometanos. Las personas buscan la felicidad conductista para ellas y para sus hijos. Saben que deben construir esta felicidad por ensayo y error — por experimentación. Ya no serán guiados por la historia y la tradición.

En Utopía (un país del tamaño del estado de Texas, con algo menos de 10.000 .000 almas), tenemos en cada unidad 260 esposas, cada una con un esposo ( $y$ con algunos esposos y esposas "de repuesto" que pueden necesitarse como sustitutos en caso de enfermedad). Cada esposo y esposa vive en casas separadas. Cada casa es lo suficientemente grande para dar a cada niño una habitación aparte, y una habitación de juego igualmente grande bien provista de ventanas y cristal de cuarzo. Cada casa está en el centro de un lote de tierra de al menos cinco acres. Además del esposo y la esposa, una asistente entrenada científicamente actúa como niñera e instructora. Excepto cuando son muy jóvenes, los niños necesitan muy poco cuidado personal.

En cada unidad hay 780 niños - tres niños por cada par de padres. Cuando la población de Utopía comienza a aumentar notablemente, los estadísticos llaman la atención al respecto y los padres comienzan a limitar sus hijos a dos. En algunos hogares tenemos dos niños y una niña y otras dos niñas y un niño. El número total de niños en la unidad es igual al número de niñas. Los niños en cada hogar dado varían en edad desde el nacimiento hasta los veinte años. Los científicos en Utopía han 
perfeccionado la leche al punto que hace innecesario que los niños sean amamantados, pues, independientemente de que la leche materna sea deseable en términos fisiológicos, en términos psicológicos no es deseable.

La madre nunca conoce la identidad de su propio hijo. Para el estudio científico, se mantiene un sistema Bertillon en el departamento de registros del hospital de modo tal que la paternidad puede establecerse si posteriores problemas de investigación así lo demandan.

Tan pronto como un niño nace, es llevado al Hogar Número Uno, donde ya hay dos niños más. El niño vive allí exactamente cuatro semanas y se le lleva a otro hogar donde también hay dos niños más. Este procedimiento continúa hasta que el infante, el niño y el joven adolescente han pasado por las manos de todas las 260 madres, habiendo permanecido sólo cuatro semanas con cada una. Habrá estado en manos de trece madres cada año. Tendrá exactamente veinte años de edad cuando su madre y padre 260 le den una palmada en la espalda y lo envíen fuera a ganarse la vida sin ayuda.

Escogimos el período de rotación de cuatro semanas porque hay poca oportunidad de que en este corto trecho de tiempo cualquier hogar pueda condicionarlo indeleble y excesivamente. Las fijaciones de la madre no se desarrollan (para la madre o para el niño). Los celos no tienen tiempo de crecer. La dependencia entre los individuos no es posible. La timidez y el sentimiento de inferioridad no pueden desarrollarse por la simple razón de que no hay estímulos en el ambiente para producirlos.

No hay suelo en Utopía donde la "posesión" de una persona por otra pueda prosperar. Por lo tanto, la minusvalía (un dispositivo por el cual un niño o un adulto perezosos, llorones y quejosos pueden controlar la conducta de otros para el provecho propio) nunca se ve. La reserva corporal de los padres está bien -las enfermedades venéreas son desconocidas - por lo tanto hay pocos o no hay casos de inferioridad orgánica en las crías. Los escasos y esporádicos casos en que los niños nacen con uno u otro tipo de defecto orgánico, son devueltos a los médicos tanto para producir una muerte sin dolor, o para experimentación o para desarrollar compensaciones especiales.

Los 520 padres de Utopía poseen formaciones ampliamente divergentes. Algunos de los padres son verdaderos Trader Horns y Daniel Boones. Otros son artesanos diestros, impresores, grabadores, trabajadores de la madera, la piedra, el mármol y el metal. Otros son manufactureros. Muchos son científicos cubriendo campos especiales como la química, la física y la medicina. Todos son versátiles y tienen una amplia experiencia en distintos negocios. Cualquiera de ellos puede comenzar desnudo en la selva de Africa y conquistar su ambiente, vestirse y alimentarse por sí mismo y construir un refugio. Todos son diestros en atletismo, boxeo, tiro y navegación. No hay clase militar. Todos aceptan a los niños como parte de la vida. Tienen tiempo para cuidarlos e instruirlos.

No hay iglesias ni clérigos en Utopía (e incidentalmente, tampoco filosofía). Los Utópicos son bastante objetivos en sus asunciones. Nunca han sido confrontados con ninguna evidencia de que existe una vida después de su vida. Nunca han observado ninguna telepatía, manifestaciones espirituales o cosas ocultas. Nunca han visto nada que no pueda ser explicado sobre una base puramente física. Creen que la religión, basada como realmente está sobre una proyección del viejo sistema familiar (sobre la idea de que hay un padre celestial, un hijo, etc.), simplemente carga consigo los males de la vida familiar que originalmente los condujeron hacia Utopía para un nuevo comienzo. 
La familia tal como la conocemos en América, como se recuerda, enseña al individuo a ser dependiente del padre y de la madre hasta la edad de veintiuno. Patrocina la dependencia a través de la adolescencia. La religión es un dispositivo para llevar esta dependencia a lo largo de la vida del individuo. A los jóvenes utópicos se les enseña a depender de sí mismos. Ninguna pérdida de fortuna o de bienes materiales los abruma.

La muerte por accidente o por vejez de adultos o de compañeros no les resulta devastadora como ocurre con la gente del resto del mundo, porque el apego fuerte (excepto el apego al compañero) no puede crecer en un Utopía. La muerte se ve como parte de la vida cotidiana y es un evento tan natural como nacer o dormir y comer. A los jóvenes utópicos se les enseña que la muerte es el fin de la existencia de un individuo, y por eso la felicidad debe buscarse en las cosas que están haciendo - debe buscarse y hallarse cada día; y si no la están encontrando entonces algo malo sucede con su entrenamiento. Necesitan más entrenamiento e instrucción. Por lo tanto, los tesoros deben acumularse aquí y no en un más allá mítico.

La religión excusa el error y la debilidad, y desde sus inicios promueve la resignación, la pereza y la ineficiencia. La oración es vista como una expresión de debilidad; como la falta de habilidad del individuo para conquistar su ambiente. Incluso en los asuntos cotidianos se enseña a los más jóvenes a apelar muy poco a la ayuda de los otros, y esto último sólo sucede después de que su propia experimentación no ha rendido buenos resultados.

Las mujeres en Utopía también han tenido una larga experiencia. Mientras se casan por primera vez a una edad muy temprana, no se les permite hacerse cargo de los niños hasta que tienen veintiocho años. Los utopistas saben que, independientemente del cuidado que se usa para criar familias, el narcisismo (usted recordará la fábula de Narciso, que se enamoró tan profundamente de su propio reflejo en el agua que no podía separarse de él) crece debido a las atenciones de los varones hacia las mujeres especialmente bellas y bien favorecidas.

A decir verdad, este es uno de los problemas más serios en Utopía. No existe en América ese problema tal como existe aquí, pues todas las mujeres en Utopía serían consideradas hermosas. La reserva de la cual estas mujeres provienen se escogió con referencia a ese punto. El narcisismo desaparece en nosotros alrededor de los veintiocho años, casi coincidiendo con la aparición de la primera arruga.

De nuevo, todas las mujeres son agraciadas y fuertes, debido a su vida al aire libre, el baile y el atletismo. Todas son de pequeña a mediana estatura. A las mujeres grandes y las ocasionalmente enfermizas no se les permite desarrollarse. No hay mujeres gordas en Utopía, ni hombres gordos. La gordura es vista del mismo modo que la incontinencia en otras funciones corporales.

No hay mujeres en la industria como tal. Allí no se las necesita. Se las necesita en la casa. Allí son felices. El trabajo de mantenerse jóvenes y bellas, útiles y de aprender la ciencia del hogar, les da toda la actividad que necesitan. No tienen tiempo para el ejercicio industrial. Ellas saben que no pueden comer el pastel y también conservarlo. Su vida es tan seria y rica en logros y esfuerzos como la vida de los hombres.

Las distintas madres y niñeras están tan bien entrenadas que el cuidado del hogar y de los niños es continuo, a pesar del hecho de que la vida en cada hogar sólo dura cuatro semanas. Tal como hoy, en casos de enfermedad, la niñera nocturna comienza a trabajar justo cuando la niñera diurna acaba su 
turno, y así otra madre se hace cargo del niño. Por lo tanto, los hábitos personales y los condicionamientos crecen perfectamente, aun cuando el niño se rota. El propósito total de esta rotación de hogares es, naturalmente, mantener neutral la base del hogar y, al mismo tiempo, dar al niño un cuidado perfecto. Obtenemos la neutralidad imposibilitando los lazos fuertes.

¿Pero ocuparse sólo de sí mismo no hace del niño un egoísta? Para nada. Nuestros niños se preocupan por todo el mundo. Pertenecen a todo el mundo y todo el mundo les pertenece.

En Utopía los médicos tienen mucha importancia en la crianza de los niños. Todos los médicos son conductistas entrenados. Para ellos, las complicaciones conductuales, que están en la base de nuestros temores - berrinches, rabietas, taciturnidad, depresiones, exaltaciones, sentimientos de inferioridad, timidez, etc. - son tan importantes como la tos ferina, la fiebre tifoidea, la tuberculosis y el cáncer. Cuidan a la comunidad tanto del lado psicológico como del lado médico. En Utopía hay una psicología preventiva así como hay una medicina preventiva. Por lo tanto los médicos asumen el cuidado cabal de todo el individuo. Cuidan a los niños como a los jóvenes y adultos.

El entrenamiento del médico requiere cierto número de años porque debe ser amplio y variado. Ninguno puede hacerse cargo de un individuo antes de cumplir los treinta años de edad. El médico es pagado por el estado. Su salario es alto —homologado al ingreso de los grandes hombres de negocio de Utopia. Cada médico tiene que mantener bien —-médica y psicológicamente — a padres e hijos hasta un número de setenta y cinco.

Posiblemente, la mayor tarea del médico sea extinguir los condicionamientos. Si los niños o adultos de su grupo muestran signos de conducta desviante, si enloquecen, si los niños muestran un trastorno emocional, si parecen ausentes, roban, o muestran reacciones sexuales anormales, el médico se hace cargo de ellos y en primer lugar extingue los condicionamientos —esto es, limpia las formas asociales de comportamiento-y luego re-condiciona o inicia el condicionamiento.

En Utopía creemos que si un hombre "se porta mal" se debe a un entrenamiento defectuoso durante la juventud $-\mathrm{y}$, por lo tanto, es culpa de la comunidad- o se debe a factores relacionados con enfermedades físicas. Así, "la mala conducta" es responsabilidad de la comunidad científica. El medico debe volver a entrenar por el lado psicológico, o debe curar la dolencia corporal. Cosas como el castigo y la prisión son extrañas en Utopía. No existen palabras como bien o mal o castigo.

Los médicos tienen bases de entrenamiento extensivo a partir de las cuales pueden re-entrenar a los individuos psicológicamente enfermos, y si un utópico deviene loco incurable o desahuciado, si aparecen niños idiotas y débiles mentales, los médicos no dudan en darles muerte. Un jurado de siete médicos vota secretamente antes de que la eutanasia se practique. El veredicto debe ser unánime en la primera votación. Si no es unánime, se deben adelantar esfuerzos médicos o psicológicos para reconstruir al individuo. Así, a los médicos se los dispensa de presenciar el ridículo espectáculo de doce ignorantes pero verdaderos jurados emitiendo juicios sobre la cordura, la culpabilidad o la inocencia. Creemos que tales decisiones deben estar en manos de especialistas.

En Utopía, la educación de los niños es nuestro interés más profundo. Hasta que los más jóvenes puedan navegar por su propia cuenta, en algún momento cerca de los tres años de edad, se los mantiene necesariamente cerca de la base del hogar. Mucho de su tiempo allí se invierte en formar 
buenos hábitos personales relacionados con dormir, comer, vestirse y desvestirse, persistencia en el trabajo, y cosas por el estilo.

El resto del tiempo se invierte en la formación de hábitos emocionales y disposicionales. Si estos hábitos no se forman temprano, el joven está condenado de por vida. Raras veces se desarrollan la timidez o el descaro excesivo. El temor a los objetos inofensivos es reducido al mínimo. El cuidado se usa para prevenir que se desarrollen los berrinches, el malhumor y la combatividad. Cuando el niño se escapa de las manos, el médico conductista es enviado para que ayude a la madre.

Cosas como pegarle a los más jóvenes, armarles bronca y otros castigos no se permiten ni en casa ni en el hospital. Es un problema de investigación enderezar al niño y mantenerlo derecho, y sólo se usan métodos probados experimentalmente.

Casi desde el momento del nacimiento el ambiente del niño se dispone para la actividad. Cada hogar tiene un patio grande rodeado por una cerca alta. El niño puede jugar solo o con otros niños sin tener que ser observado por adultos. Cada hogar está equipado con un periscopio de modo tal que los padres puedan observar de vez en cuando al niño sin ser vistos. El niño aprende a hacer sus cosas sin tener que llamar la atención. No lo rodea una profusión de objetos y juguetes. Desde el principio, se pone énfasis en que tenga contacto con la materia prima y haga algo con ella. Hay tierra suave para que cave; hay piedras, palos, tablas, cuerdas y herramientas. Su ambiente se mantiene tan fronterizo como sea posible durante sus primeros años. Progresivamente se va haciendo más complejo y difícil. Las dificultades abundan, aunque siempre se tiene a mano la materia prima la cual, si se la usa correctamente, lo ayudará con sus dificultades. Hoy, en Utopía, un niño de seis años y otro de cuatro cavaron durante cuatro horas los cimientos de una casa de juguete. Nunca hubo una pelea. Ni siquiera voltearon a mirar cuando un perro se acercó a ellos. Estaban absortos en su actividad.

Esta absorción absoluta en una actividad es la clave de la felicidad de nuestros niños. Es nuestra definición de felicidad conductista.

A los tres años, o antes, los niños y niñas comienzan la escuela -la misma escuela. No hay escuelas de chicas ni escuelas de chicos, no hay campamentos de chicos ni campamentos de chicas. De nuevo, la escuela no es un lugar de manuales, sino un lugar donde se implican en actividades variadas y complicadas siguiendo la guía de especialistas. El aprendizaje se logra haciendo, con el joven hallándose a sí mismo en situaciones más y más difíciles y librándose de ellas por ensayo y error. La escuela duplica en miniatura todas las actividades de Utopía. Para los muy jóvenes la duplicación es necesariamente muy inexacta. A medida que el niño se hace más diestro sus nuevas actividades se hacen más complicadas — se parecerán más a las actividades adultas de los utópicos.

A la edad de dieciséis el entrenamiento de las chicas se diferencia del entrenamiento de los chicos. Los niños se convierten en aprendices de ciencia, medicina, manufactura, arquitectura, minería, agricultura. Cuando el chico tiene veinte, pasa al campo de la ciencia o de la industria sin interrupción. Durante el período que va de los dieciséis a los veinte, los chicos prueban en varias industrias, y hacen una selección de la vocación que perseguirán el resto de sus vidas. No hay tal cosa como una universidad o una escuela técnica. La industria o la ciencia son las escuelas donde aprenden.

A los dieciséis cada chica aprende cómo llevar un hogar. Aprende todo, desde planificar el interior de una casa hasta diseñar los tapetes y mantelería que van en ella. Las chicas aprenden la ciencia 
doméstica, cocina, dietética. Tienen una formación especial en el arte de interesar y de manejar a los hombres. Se les enseña el arte y la técnica de estar comprometidas. Invierten mucho tiempo aprendiendo la técnica del sexo. Tienen que aprender a ser niñeras y se las instruye especialmente en el cuidado, manejo y enseñanza de los bebes y de jóvenes de todas las edades.

Aprenden cómo llevar un hogar - tal como los chicos aprenden sus trabajos- yendo a casas, restaurantes, y hospitales y trabajando allí. Estudian decoración de interiores y el diseño de muebles, y de adornos, y de sus propios vestidos y sombreros. Están ocupadas y felices de la mañana a la noche. Es durante esta edad que comienzan con entusiasmo el estudio de la danza, del uso de cosméticos, de cómo mantenerse delgadas, de cómo ser anfitrionas exitosas, y asumir los conocimientos intelectuales que van con la hechura de una mujer bella, graciosa y sabia.

Las mujeres jóvenes de Utopía sienten y actúan tan libremente como los hombres. Tienen mucho respeto por el arte y la ciencia de ser una mujer exitosa. La presión social también mantiene a las mujeres lejos de competir con los hombres - tal como en América las mujeres se mantienen al margen de la navegación, de ser porteras en los trenes, de ser estibadoras, ingenieras ferroviarias, y trabajos por el estilo.

Por ahora, nuestra manera de manipular a los niños ha demostrado ser segura y sana. Nunca en la historia de la humanidad ha habido una juventud semejante. En los infantes uno raras veces escucha un llanto o ve un berrinche, aunque no carecen de esa chispa de vida emocional que diferencia a un individuo de otro. Son sociales aunque saben cómo lidiar consigo mismos cuando están solos.

Nunca hay problemas respecto de lo que ha de hacerse con los jóvenes. Basta ubicarlos en cualquier lugar, en cualquier tipo de trabajo, ante cualquier tipo de persona sea un magnate ferroviario o un labriego, y se sentirán como en casa. Ser diestro para cualquier actividad sosiega y elimina los temores de cara al futuro. $Y$ están entrenados para vivir juntos como miembros de comunidades, como trabajadores y técnicos, como hombre y esposa. Con habitantes como estos no es de extrañar que no necesitemos de esa entidad abstracta que llamamos Estado.

Fin

\section{Formato de citación}

Watson, John B. (2009). ¿Debería un niño tener más de una madre?. Athenea Digital, 15, 193-201. Disponible en http://psicologiasocial.uab.es/athenea/index.php/atheneaDigital/article/view/4.

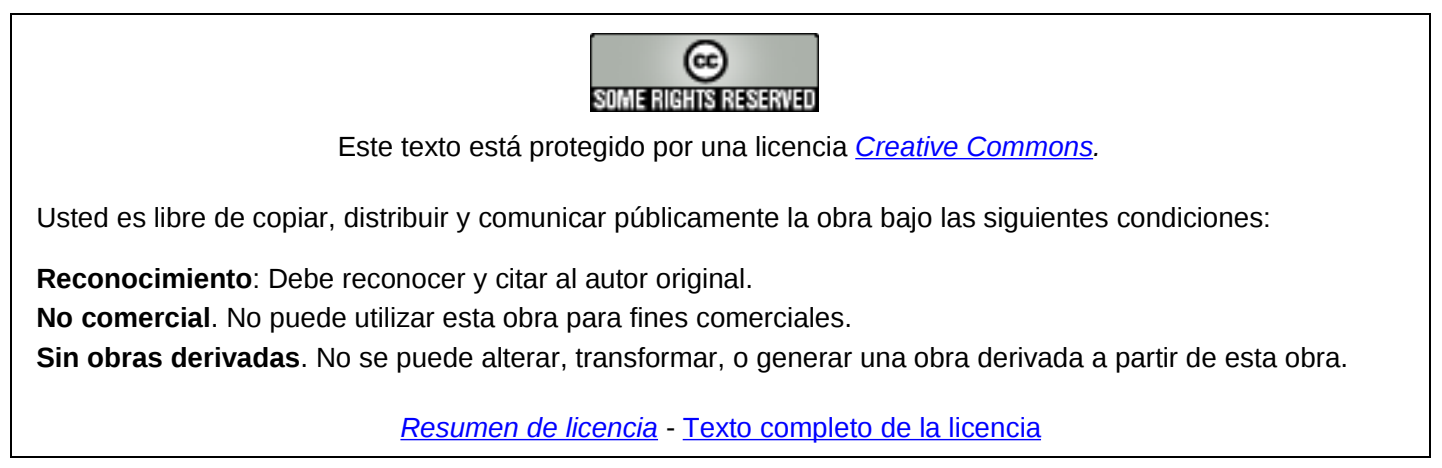


